\title{
EFFECT OF FORMULATION FACTORS ON ORODISPERSIBLE TRIPTAN FORMULATIONS - NOVEL APPROACH IN TREATMENT OF MIGRAINE
}

\author{
YELLA SIRISHA ${ }^{1 *}$, GOPALA KRISHNA MURTHY T E ${ }^{2}$, AVANAPU SRINIVASA RAO ${ }^{3}$
}

${ }^{1}$ Department of Pharmaceutics, Bhaskar Pharmacy College, Yenkapally, Moinabad, Hyderabad, Telangana - 500 075, India. ${ }^{2}$ Department of Pharmaceutics, Bapatla College of Pharmacy, Bapatla, Guntur, Andhra Pradesh - 522 101, India. ${ }^{3}$ Department of Pharmacology, Bhaskar Pharmacy College, Yenkapally, Moinabad, Telangana - 500575, India. Email: sirisha.pharma21@gmail.com

Received: 01 November 2017, Revised and Accepted: 4 December 2017

ABSTRACT

Objective: The present research work is an attempt to determine the effect of various diluents and superdisintegrants on drug release of eletriptan orodispersible tablets and designs an optimized formulation using $2^{2}$ factorial design. Further, evaluate the tablets for various pre-compression and post-compression parameters.

Methods: The drug excipient compatibility study was conducted by infrared spectroscopy, differential scanning colorimetry and X-ray diffraction studies were conducted to test the purity of the drug. The tablets were formulated by direct compression method using spray dried lactose, mannitol, microcrystalline cellulose, starch as diluents and crospovidone, croscarmellose sodium, and sodium starch glycolate as superdisintegrants. The powder formulations were evaluated for pre-compression parameters such as bulk density, tapped density, Carr's Index, Hausner's ratio, and angle of repose. The tablets were evaluated for post-compression parameters such as the hardness, thickness, friability, weight variation, and disintegrating time in the oral cavity, in vitro drug release kinetics studies, and accelerated stability studies. The formulations were optimized by $2^{2}$ factorial design.

Results: The drug and excipients were compatible, and no interaction was found. The drug was pure, and all the pre-compression parameters were within Indian Pharmacopoeial Limits. Post-compression parameters were also within limits. The disintegration time was found to be $27 \mathrm{~s}$ for the formulation $\mathrm{F}_{29}$ containing Croscarmellose sodium (5\%) and Mannitol as diluent, and in vitro drug release was found to be $99.67 \%$ in 30 min and follows first-order kinetics. This was also the optimized formulation by $2^{2}$ factorial design with a $\mathrm{p}=0.013$.

Conclusion: The orodispersible tablets of eletriptan were successfully formulated, and the optimized formulation was determined that can be used in the treatment of migraine.

Keywords: Eletriptan, Crospovidone, Croscarmellose sodium, Sodium starch glycolate, Microcrystalline cellulose, Lactose, Starch, Magnesium stearate, Talc, Aerosil, Aspartame.

(C) 2018 The Authors. Published by Innovare Academic Sciences Pvt Ltd. This is an open access article under the CC BY license (http://creativecommons. org/licenses/by/4. 0/) DOI: http://dx.doi.org/10.22159/ajpcr.2018.v11i3.23401

\section{INTRODUCTION [1]}

Oral route of drug administration is perhaps most useful and important route for drug delivery. Tablets are the most favored oral solid dosage form mainly because of several advantages such as ease of administration, good chemical and microbiological stability, lowest cost among all another solid dosage form, dose precision and least content variability, ease of packing, self-medication, and patient compliance. Orodispersible tablets are solid unit dosage forms like conventional tablets, but are composed of superdisintegrants, which help them to dissolve the tablets within a minute in the mouth in the presence of saliva without any difficulty of swallowing. In such cases, bioavailability of the drug is significantly greater than those observed from the conventional tablet dosage form. Migraine is a neurological disease characterized by recurrent moderate to severe headaches often in association with a number of autonomic nervous system symptoms. Triptans are a family of tryptamine-based drugs used as abortive medication in the treatment of migraines and cluster headaches. Thus, the aim of present research work was to formulate oral disintegrating tablets of Eletriptan to overcome the adverse effects of conventional tablets in the treatment of migraine.

\section{METHODS}

Eletriptan was obtained as a gift sample from Sun pharma ltd, Hyderabad, croscarmellose sodium, sodium starch glycolate, crosspovidone, microcrystalline cellulose, mannitol, spray-dried lactose, and starch were obtained from Signet chemical corp. Mumbai, aspartame, aerosil, talc, and magnesium stearate were obtained from S.D fine chemicals, Mumbai, and potassium dihydrogen orthophosphate and sodium hydroxide were obtained from Narmada chemicals.

\section{Calibration curve for eletriptan in 6.8 phosphate buffer [2]}

About 100 mg of Eletriptan was accurately weighed into 100 mlvolumetric flask and dissolved in a small quantity of methanol. The volume was made up to $100 \mathrm{ml}$ with $\mathrm{pH} 6.8$ phosphate buffer to get a concentration of $(1000 \mu \mathrm{g} / \mathrm{ml})$ SS-I. From this, $1 \mathrm{ml}$ was withdrawn and diluted to 100 $\mathrm{ml}$ with 6.8 phosphate buffer to get a concentration of $(10 \mu \mathrm{g} / \mathrm{ml}) \mathrm{SS}$ II. From the standard stock solution (SS-II), $2 \mathrm{ml}, 4 \mathrm{ml}, 6 \mathrm{ml}$, and $8 \mathrm{ml}$ were withdrawn, and volume was made up to $10 \mathrm{ml}$ with 6.8 phosphate buffer to give a concentration of 2,4,6, and $8 \mu \mathrm{g} / \mathrm{ml}$. Absorbance of these solutions was measured against a blank of 6.8 phosphate buffer at $221 \mathrm{~nm}$, and values are tabulated in Table 4 and shown in Fig 1.

Drug-excipient compatibility studies by infrared (IR)[3]

IR spectroscopy is one of the most powerful analytical techniques to identify functional groups of a drug. The pure drug and its formulation were subjected to IR studies. In the present study, the potassium bromide disc (pellet) method was employed. The graphs are shown in Fig. 2 and 3.

Formulation of orodispersible tablets of Eletriptan[3]

All the ingredients were weighed accordingly and passed through\#60 mesh sieve separately. The drug and diluents were mixed by adding a 
small portion of each at a time and blending it to get a uniform mixture and kept aside. Then, the other ingredients were mixed in geometrical order and passed through a coarse sieve (\#44 mesh), and the tablets were compressed using hydraulic press. Compression force of the machine was adjusted to obtain the hardness in the range of 3-4 kg/ $\mathrm{cm}^{2}$ for all batches. The formulations are given in Tables 1 and 2 .

\section{Pre-compression parameters}

Method preparation of mixed blend of drug and excipients

All the materials were passed through sieve no. 80. Required quantity of each ingredient was taken for each specified formulation (Mentioned in Tables 1 and 2), and all the ingredients were subjected to grinding to a

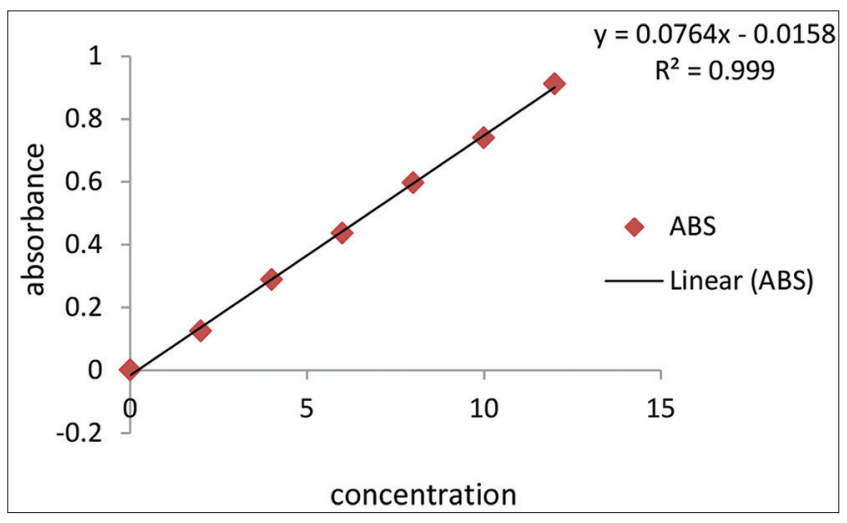

Fig. 1: Standard calibration curve of Eletriptan in pH 6.8 phosphate buffer required degree of fineness (except magnesium stearate and talc). The powdered blend was evaluated for flow properties as follows.

\section{Angle of repose[4]}

Angle of repose is determined using funnel method. The accurately weighed blend is taken in a funnel. The height of the funnel is adjusted in such a way that the tip of the funnel just touches the apex of the heap of blend. The drug-excipient blend is allowed to flow through the funnel freely on to the surface. The diameter of the powder cone is measured, and angle of repose is calculated using the following equation. Angle of Repose $<30^{\circ}$ shows the free flowing of the material. Values are given in Table 5 .

$\theta=\tan -1(\mathrm{~h} / \mathrm{r})$

\section{Bulk density [4]}

Apparent bulk density is determined by pouring a weighed quantity of blend into a graduated cylinder and measuring the volume and weight. Listed the values in Table 5.

The bulk density was calculated using the below-mentioned formula

$$
\mathrm{D}_{\mathrm{b}}=\frac{\mathrm{M}}{\mathrm{Vo}_{\mathrm{o}}}
$$

Where, $\mathrm{M}$ is the mass of powder, $\mathrm{V}_{0}$ is the bulk volume of the powder

\section{Tapped density[4]}

It is determined by placing a graduated cylinder, containing a known mass of drug-excipients blend. The cylinder is allowed to fall under its own weight onto a hard surface from the height of $10 \mathrm{~cm}$ at $2 \mathrm{~s}$ intervals. The tapping is continued until no further change in volume is noted.

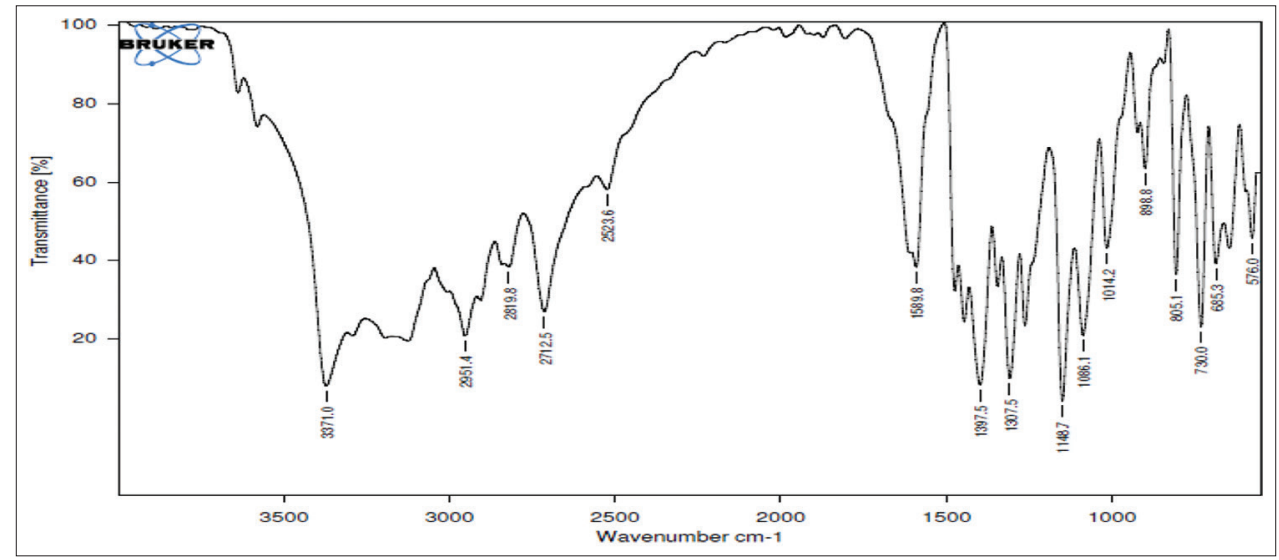

Fig. 2: Fourier-transform infrared spectroscopy of Eletriptan pure drug

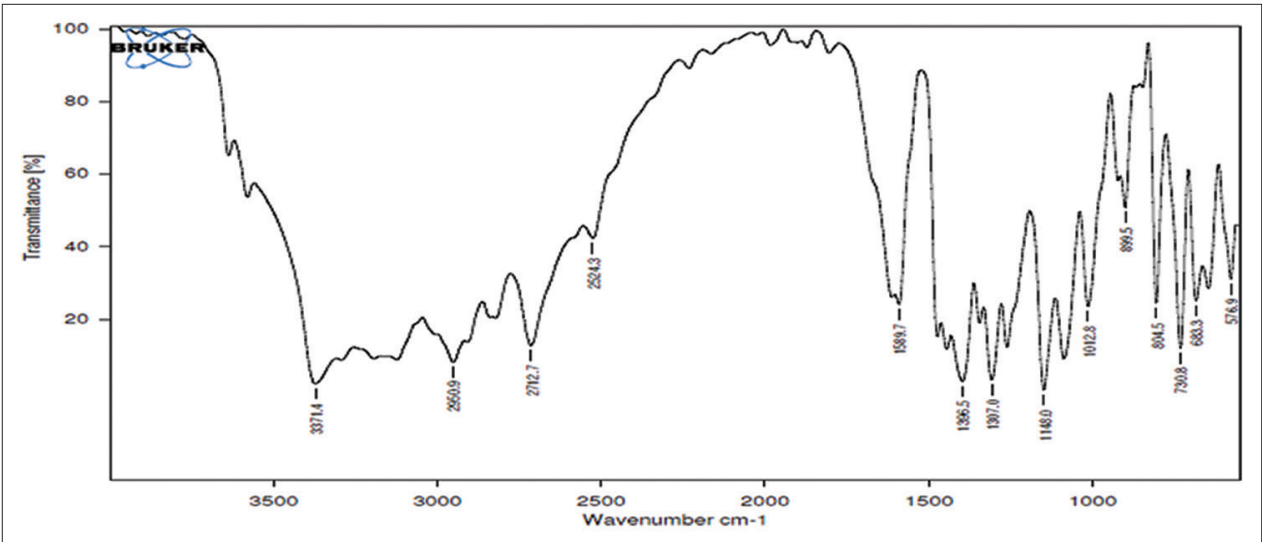

Fig. 3: Fourier-transform infrared spectroscopy of Eletriptan optimized formulation 
Table 1: Formulations of Eletriptan using various diluents

\begin{tabular}{|c|c|c|c|c|c|c|c|c|c|c|c|c|c|c|c|c|}
\hline Form. Code & $F_{1}$ & $\mathbf{F}_{2}$ & $\mathbf{F}_{3}$ & $\mathrm{~F}_{4}$ & $\mathbf{F}_{5}$ & $\mathbf{F}_{6}$ & $\mathbf{F}_{7}$ & $F_{8}$ & $F_{9}$ & $F_{10}$ & $F_{11}$ & $F_{12}$ & $F_{13}$ & $F_{14}$ & $F_{15}$ & $F_{16}$ \\
\hline Eletriptan & 20 & 20 & 20 & 20 & 20 & 20 & 20 & 20 & 20 & 20 & 20 & 20 & 20 & 20 & 20 & 20 \\
\hline SSG & 10 & 10 & 10 & 10 & 10 & 10 & 10 & 10 & 10 & 10 & 10 & 10 & 10 & 10 & 10 & 10 \\
\hline Starch & 100 & 120 & 140 & 160 & & & & & & & & & & & & \\
\hline MCC & & & & & 100 & 120 & 140 & 160 & & & & & & & & \\
\hline Mannitol & & & & & & & & & 100 & 120 & 140 & 160 & & & & \\
\hline Spray dried lactose & & & & & & & & & & & & & 100 & 120 & 140 & 160 \\
\hline Aspartame & 10 & 10 & 10 & 10 & 10 & 10 & 10 & 10 & 10 & 10 & 10 & 10 & 10 & 10 & 10 & 10 \\
\hline Mg stearate & 4 & 4 & 4 & 4 & 4 & 4 & 4 & 4 & 4 & 4 & 4 & 4 & 4 & 4 & 4 & 4 \\
\hline Talc & 4 & 4 & 4 & 4 & 4 & 4 & 4 & 4 & 4 & 4 & 4 & 4 & 4 & 4 & 4 & 4 \\
\hline
\end{tabular}

Table 2: Formulations of Eletriptan using optimized diluent and various superdisintegrants

\begin{tabular}{|c|c|c|c|c|c|c|c|c|c|c|c|c|c|c|c|c|c|}
\hline Form code & $F_{17}$ & $F_{18}$ & $F_{19}$ & $F_{20}$ & $F_{21}$ & $\mathbf{F}_{22}$ & $\mathbf{F}_{23}$ & $\mathbf{F}_{24}$ & $\mathbf{F}_{25}$ & $F_{26}$ & $\mathbf{F}_{27}$ & $F_{28}$ & $F_{29}$ & $\mathbf{F}_{30}$ & $\mathbf{F}_{31}$ & $\mathbf{F}_{32}$ & $\mathbf{F}_{33}$ \\
\hline Eletriptan & 20 & 20 & 20 & 20 & 20 & 20 & 20 & 20 & 20 & 20 & 20 & 20 & 20 & 20 & 20 & 20 & 20 \\
\hline SSG & 4 & 6 & 8 & 10 & 12 & 14 & 16 & & & & & & & & & & \\
\hline CCS & & & & & & & & 1 & 2 & 4 & 6 & 8 & 10 & & & & \\
\hline $\mathrm{CP}$ & & & & & & & & & & & & & & 4 & 6 & 8 & 10 \\
\hline Mannitol & 140 & 140 & 140 & 140 & 140 & 140 & 140 & 140 & 140 & 140 & 140 & 140 & 140 & 140 & 140 & 140 & 140 \\
\hline Aspartame & 10 & 10 & 10 & 10 & 10 & 10 & 10 & 10 & 01 & 01 & 10 & 10 & 10 & 10 & 10 & 10 & 10 \\
\hline Aerosil & 2 & 2 & 2 & 2 & 2 & 2 & 2 & 2 & 2 & 2 & 2 & 2 & 2 & 2 & 2 & 2 & 2 \\
\hline Talc & 4 & 4 & 4 & 4 & 4 & 4 & 4 & 4 & 4 & 4 & 4 & 4 & 4 & 4 & 4 & 4 & 4 \\
\hline
\end{tabular}

CCS: Cross carmellose sodium, CP: Crospovidone, SSG: Sodium starch glycolate

Table 3: Representing the statistical analysis ANOVA and the resultant values for best formulation

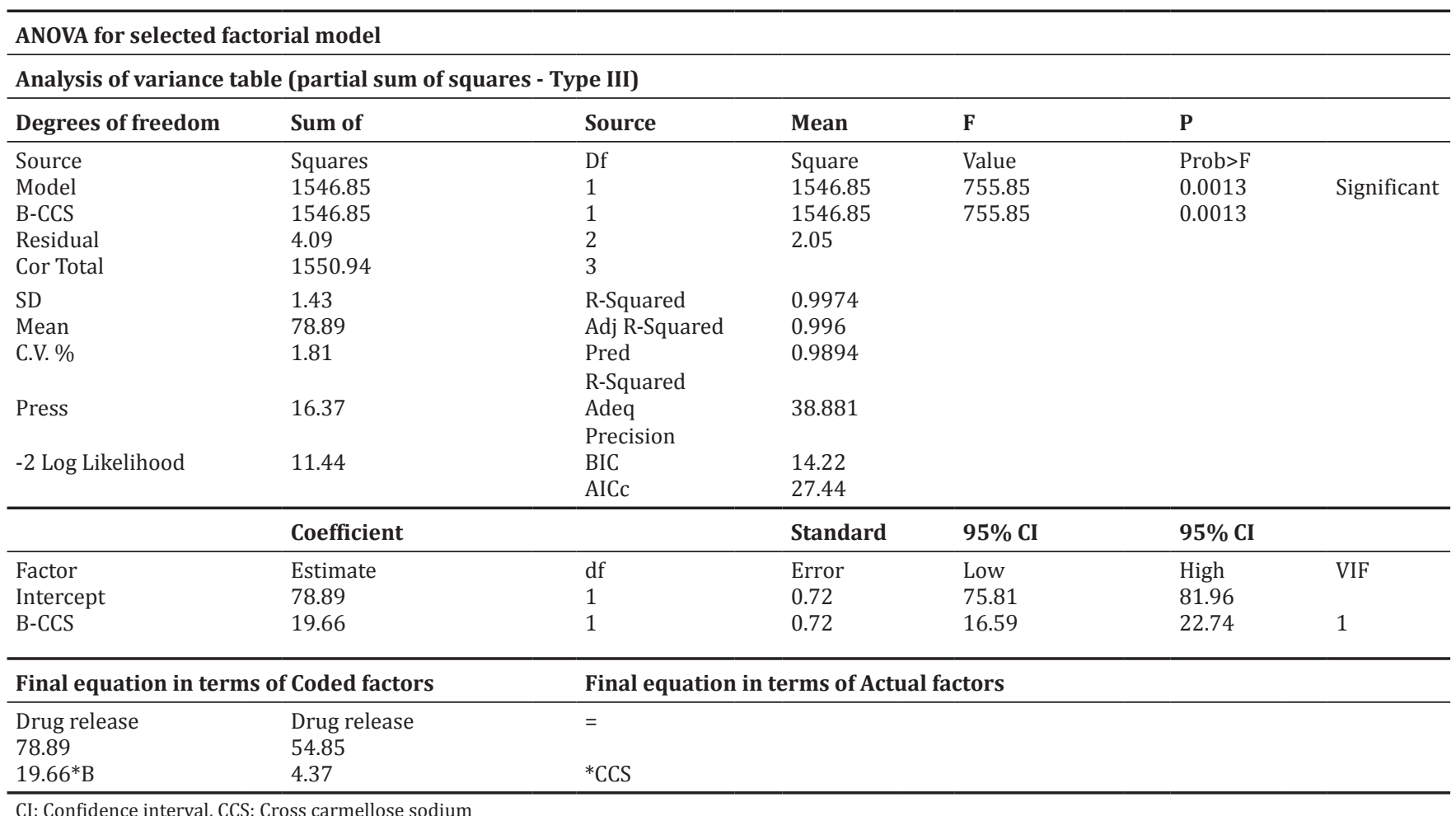

The tapped density was calculated using the following formula,

$$
\mathrm{D}_{\mathrm{T}}=\frac{\mathrm{M}}{\mathrm{Vt}}
$$

Where, $\mathrm{M}$ is the mass of powder, $\mathrm{V}_{\mathrm{T}}$ is the tapped volume of the powder

The values are given in Table 5.
Compressibility index[5]

The simplest way for measurement of free flow of powder is compressibility, an indication of the ease with which a material can be induced to flow is given by compressibility index(I) which is calculated as follows and the values are given in Table 5.

$$
\mathrm{R}=\frac{\mathrm{W} 2-\mathrm{W} 1}{\mathrm{~W} 2-\mathrm{W} 1} \times 100
$$


The value between 13 and 19\% indicates a powder with usually good flow characteristics, whereas above $21 \%$ indicate poor flowability.

\section{Hausner's ratio [5]}

Hausner's ratio is an indirect index of ease of powder flow. It is calculated by the following formula

$$
\text { Hausner's Ratio }=\frac{\text { TappedDensity }}{\text { Bulk Density }}
$$

Where $\mathrm{D}_{\mathrm{t}}$ is tapped density and $\mathrm{D}_{\mathrm{b}}$ is bulk density

Lower Hausner's ratio $(<1.25)$ indicates better flow properties and higher Hausner's ratio $(>1.25)$ indicates poor flow properties. The values are listed in Table 5.

Table 4: Standard calibration curve of Eletriptan in phosphate buffer $\mathrm{pH} 6.8$ at $\lambda_{\max } 221 \mathrm{~nm}$

\begin{tabular}{ll}
\hline Conc & Abs \\
\hline 0 & $0 \pm 0.000$ \\
2 & $0.124 \pm 0.012$ \\
4 & $0.288 \pm 0.014$ \\
6 & $0.436 \pm 0.022$ \\
8 & $0.597 \pm 0.034$ \\
6 & $0.74 \pm 0.014$ \\
12 & $0.912 \pm 0.033$ \\
\hline
\end{tabular}

Evaluation of mouth dissolving tablets

Thickness and diameter [6]

Tablet thickness and diameter can be measured using a simple procedure. Five tablets are taken, and their thickness is measured using Vernier calipers. The thickness and diameter are measured by placing tablet between two arms of the Vernier calipers. Values have been tabulated in Table 6.

\section{Weight variation test [6]}

The weight variation test is carried out to ensure uniformity in the weight of tablets in a batch. First, the total weight of 20 tablets from each formulation is determined, and the average is calculated. The individual weight of each tablet is also determined to find out the weight variation. Values have been tabulated in Table 6.

\section{Tablet hardness [7]}

The hardness of tablet is an indication of its strength. It is the force required to break a tablet by compression in the radial direction. The force is measured in $\mathrm{kg}$, and the hardness of about $3-5 \mathrm{~kg} / \mathrm{cm}^{2}$ is considered to be satisfactory for uncoated tablets. Hardness of 10 tablets from each formulation is determined by Monsanto hardness tester, Pfizer hardness tester, etc. Excessive hardness significantly reduces the disintegration time. Values have been tabulated in Table 6 .

\section{Tablet friability [7]}

Friability is the loss of weight of tablet in the container due to the removal of fine particles from the surface. Friability test is carried out to access the ability of the tablet to withstand abrasion in packaging, handling, and transport. Roche friabilator is employed for finding the

Table 5: Experimental values of Pre-compression parameters

\begin{tabular}{|c|c|c|c|c|c|}
\hline \multirow[t]{3}{*}{ Formulation Code } & \multicolumn{2}{|c|}{ Derived properties } & \multicolumn{3}{|l|}{ Flow properties } \\
\hline & \multicolumn{5}{|l|}{$($ mean $\pm S D)$} \\
\hline & Bulk density & Tapped density & Angle of repose & Carr's index & Hausner's ratio \\
\hline $\mathrm{F}_{1}$ & $0.523 \pm 0.14$ & $0.596 \pm 0.07$ & $20.14 \pm 0.16$ & $12.24 \pm 1.97$ & $1.13 \pm 0.35$ \\
\hline $\mathrm{F}_{2}^{1}$ & $0.530 \pm 0.23$ & $0.589 \pm 0.52$ & $19.66 \pm 0.02$ & $10.01 \pm 0.87$ & $1.11 \pm 0.22$ \\
\hline $\mathrm{F}_{3}^{2}$ & $0.536 \pm 0.01$ & $0.595 \pm 0.03$ & $21.03 \pm 0.30$ & $9.91 \pm 1.14$ & $1.11 \pm 0.78$ \\
\hline $\mathrm{F}_{4}^{3}$ & $0.541 \pm 0.41$ & $0.606 \pm 0.47$ & $20.65 \pm 0.11$ & $10.72 \pm 0.26$ & $1.12 \pm 0.46$ \\
\hline $\mathrm{F}_{6}^{5}$ & $0.523 \pm 0.08$ & $0.597 \pm 0.12$ & $21.56 \pm 0.32$ & $12.39 \pm 1.01$ & $1.14 \pm 0.25$ \\
\hline $\mathrm{F}_{7}^{6}$ & $0.530 \pm 0.11$ & $0.611 \pm 0.10$ & $18.99 \pm 0.21$ & $13.25 \pm 0.85$ & $1.15 \pm 0.50$ \\
\hline $\mathrm{F}_{8}^{\prime}$ & $0.556 \pm 0.14$ & $0.620 \pm 0.33$ & $23.10 \pm 0.04$ & $10.32 \pm 0.75$ & $1.11 \pm 0.69$ \\
\hline $\mathrm{F}_{9}^{8}$ & $0.511 \pm 0.74$ & $0.585 \pm 0.78$ & $21.13 \pm 0.77$ & $12.64 \pm 0.63$ & $1.14 \pm 0.21$ \\
\hline $\mathrm{F}_{10}^{9}$ & $0.527 \pm 0.85$ & $0.610 \pm 0.02$ & $22.30 \pm 0.14$ & $13.60 \pm 0.07$ & $1.15 \pm 0.01$ \\
\hline $\mathrm{F}_{11}^{10}$ & $0.541 \pm 0.09$ & $0.623 \pm 0.14$ & $22.07 \pm 0.20$ & $13.16 \pm 0.13$ & $1.15 \pm 0.45$ \\
\hline $\mathrm{F}_{12}^{11}$ & $0.545 \pm 0.52$ & $0.631 \pm 0.95$ & $23.44 \pm 0.41$ & $13.62 \pm 0.49$ & $1.15 \pm 0.66$ \\
\hline $\mathrm{F}_{13}^{12}$ & $0.518 \pm 0.36$ & $0.593 \pm 0.44$ & $21.47 \pm 0.35$ & $12.64 \pm 0.22$ & $1.14 \pm 0.90$ \\
\hline $\mathrm{F}_{15}^{14}$ & $0.533 \pm 0.72$ & $0.613 \pm 0.55$ & $23.17 \pm 0.23$ & $13.05 \pm 0.08$ & $1.15 \pm 0.03$ \\
\hline $\mathrm{F}_{16}^{15}$ & $0.539 \pm 0.03$ & $0.620 \pm 0.01$ & $21.46 \pm 0.55$ & $13.06 \pm 0.97$ & $1.15 \pm 0.70$ \\
\hline $\mathrm{F}_{17}^{16}$ & $0.564 \pm 0.12$ & $0.651 \pm 0.18$ & $22.53 \pm 0.30$ & $13.36 \pm 0.22$ & $1.15 \pm 0.66$ \\
\hline $\mathrm{F}_{18}^{17}$ & $0.551 \pm 0.21$ & $0.643 \pm 0.09$ & $21.13 \pm 0.36$ & $14.30 \pm 0.73$ & $1.16 \pm 0.75$ \\
\hline $\mathrm{F}_{19}^{18}$ & $0.537 \pm 0.45$ & $0.642 \pm 0.11$ & $22.04 \pm 0.81$ & $16.35 \pm 0.64$ & $1.19 \pm 0.12$ \\
\hline $\mathrm{F}_{20}^{19}$ & $0.566 \pm 0.78$ & $0.659 \pm 0.92$ & $23.42 \pm 0.77$ & $14.11 \pm 0.23$ & $1.16 \pm 0.91$ \\
\hline $\mathrm{F}_{21}^{20}$ & $0.570 \pm 0.41$ & $0.677 \pm 0.48$ & $24.47 \pm 0.54$ & $15.80 \pm 0.95$ & $1.18 \pm 0.85$ \\
\hline $\mathrm{F}_{22}^{21}$ & $0.536 \pm 0.33$ & $0.604 \pm 0.87$ & $20.06 \pm 0.22$ & $11.25 \pm 0.36$ & $1.12 \pm 0.41$ \\
\hline $\mathrm{F}_{23}^{22}$ & $0.542 \pm 0.25$ & $0.626 \pm 075$ & $22.55 \pm 0.36$ & $13.41 \pm 0.41$ & $1.15 \pm 0.22$ \\
\hline $\mathrm{F}_{24}^{23}$ & $0.550 \pm 0.64$ & $0.639 \pm 0.66$ & $24.12 \pm 0.77$ & $13.92 \pm 0.11$ & $1.16 \pm 0.61$ \\
\hline $\mathrm{F}_{25}^{24}$ & $0.540 \pm 0.11$ & $0.627 \pm 0.34$ & $23.63 \pm 0.33$ & $13.87 \pm 0.02$ & $1.16 \pm 0.49$ \\
\hline $\mathrm{F}_{26}^{25}$ & $0.562 \pm 0.16$ & $0.657 \pm 0.23$ & $22.10 \pm 0.22$ & $14.45 \pm 0.63$ & $1.16 \pm 0.07$ \\
\hline $\mathrm{F}_{27}^{20}$ & $0.535 \pm 0.22$ & $0.611 \pm 0.12$ & $23.14 \pm 0.41$ & $12.43 \pm 0.47$ & $1.14 \pm 0.10$ \\
\hline $\mathrm{F}_{28}^{21}$ & $0.540 \pm 0.41$ & $0.632 \pm 0.74$ & $22.56 \pm 0.97$ & $14.55 \pm 0.25$ & $1.17 \pm 0.99$ \\
\hline $\mathrm{F}_{29}^{28}$ & $0.526 \pm 0.88$ & $0.599 \pm 0.55$ & $22.09 \pm 0.85$ & $12.18 \pm 0.36$ & $1.13 \pm 0.15$ \\
\hline $\mathrm{F}_{30}^{29}$ & $0.546 \pm 0.36$ & $0.635 \pm 0.48$ & $21.78 \pm 0.36$ & $14.05 \pm 0.98$ & $1.16 \pm 0.34$ \\
\hline $\mathrm{F}_{31}^{30}$ & $0.533 \pm 0.97$ & $0.615 \pm 0.02$ & $20.71 \pm 0.69$ & $13.33 \pm 0.87$ & $1.15 \pm 0.66$ \\
\hline
\end{tabular}


Table 6: Experimental values of post-compression parameters

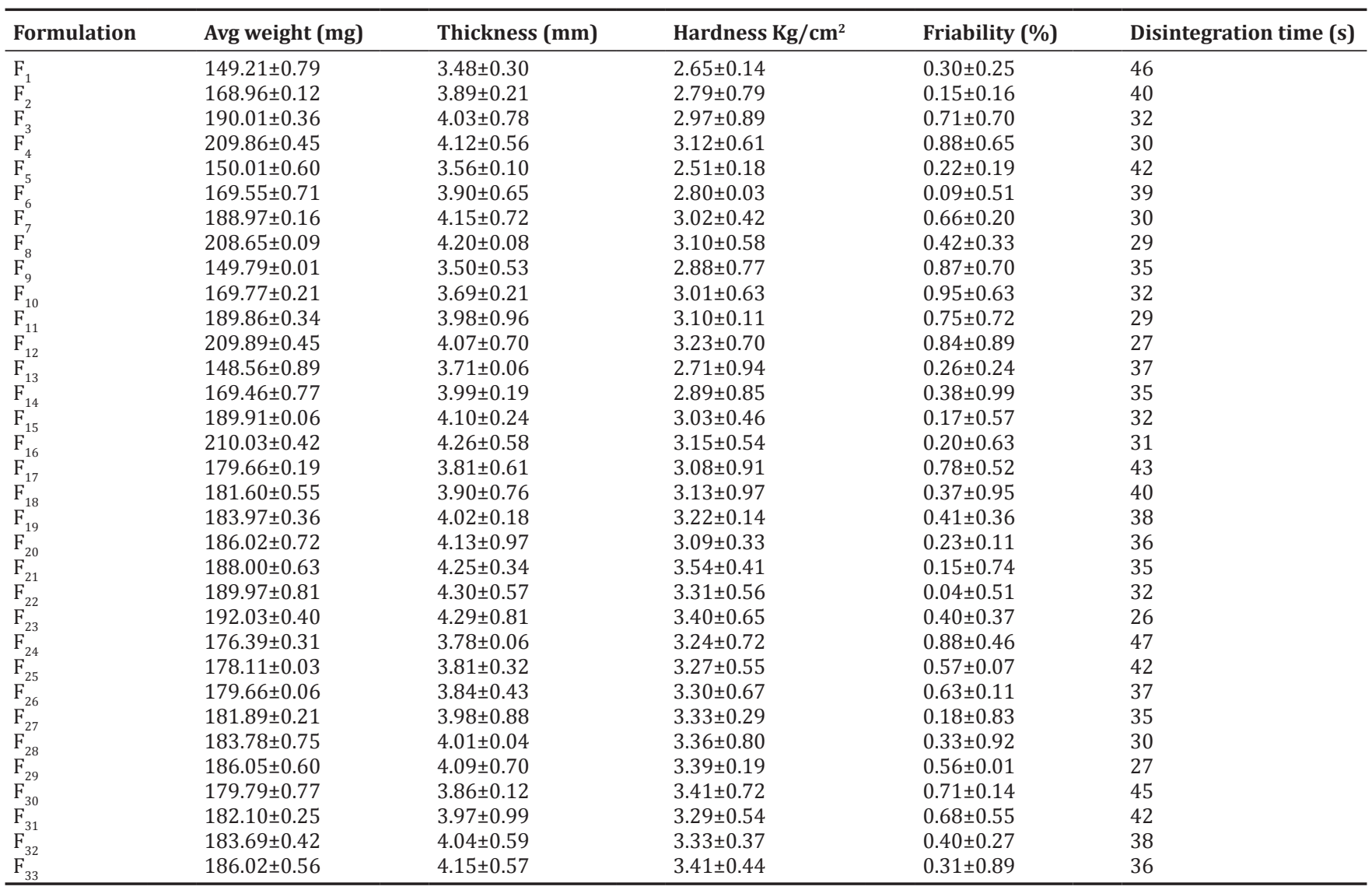

friability of the tablets. Weigh the 20 tablets from each batch and place in Roche friabilator that will rotate at $25 \mathrm{rpm}$ for $4 \mathrm{~min}$. All the tablets are dedusted and weighed again. The percentage of friability can be calculated using the formula. Values have been tabulated in Table 6.

$$
\% \text { Friability }=\frac{\mathrm{W} 1-\mathrm{W} 2}{\mathrm{~W} 2} \times 100
$$

Where, $\mathrm{W} 1=$ Weight of tablet before test, $\mathrm{W} 2=$ =Weight of tablet after test

\section{In vitro disintegration time[8]}

Tablet disintegration is an important step in drug absorption. The test for disintegration was carried out in Electrolab USP disintegration test apparatus. It consists of 6 glass tubes which are 3 inches long, open at the top, and held against a 10 mesh screen, at the bottom end of the basket rack assembly. To test the disintegration time of tablets, one tablet was placed in each tube, and the basket rack was positioned in a $1 \mathrm{~L}$ beaker containing $\mathrm{pH} 6.8$ buffer solution at $37^{\circ} \mathrm{C} \pm 1^{\circ} \mathrm{C}$ such that the tablet remains $2.5 \mathrm{~cm}$ below the surface of the liquid. The time taken for the complete disintegration of the tablets was noted. Values have been tabulated in Table 6.

\section{Wetting time[9]}

The formulated tablets were taken and were placed individually in the Petri plate containing dye added buffer solution on the filter papers. The time taken for the solution to completely wet the tablet was noted by observing the transfer of dye color from bottom to the top of the tablet. Values have been tabulated in Table 7.

\section{Water absorption ratio[9]}

The tablets were initially weighed, and the weight was noted as W1. Then they were evaluated for wetting time, and the tablet weight after complete wetting was noted as $\mathrm{W} 2$. The water absorption ratio can be calculated from the formula. Values have been tabulated in Table 7.

$$
\mathrm{R}=\frac{\mathrm{W} 2-\mathrm{W} 1}{\mathrm{~W} 2-\mathrm{W} 1} \times 100
$$

\section{Drug content [10]}

The tablets were tested for their drug content uniformity. At random 20 tablets were weighed and powdered. The powder equivalent to $25 \mathrm{mg}$ was weighed accurately and dissolved in $100 \mathrm{ml}$ of suitable buffer solution. The solution was shaken thoroughly. The undissolved matter was removed by filtration through Whatman No.41 filter paper. Then, the dilute the solution to obtain $10 \mu \mathrm{g}$ solution. The absorbance of the diluted solutions was measured at $221 \mathrm{~nm}$. The concentration of the drug was computed from the standard curve. Values have been tabulated in Table 7 .

\section{Dissolution studies [10]}

In vitro dissolution study is performed using USP Type II Apparatus (Paddle type) at $50 \mathrm{rpm}$. Phosphate buffer $\mathrm{pH} 6.8,900 \mathrm{ml}$ is used as dissolution medium which is maintained at $37 \pm 0.5^{\circ} \mathrm{C}$. Aliquots of dissolution medium $(10 \mathrm{ml})$ are withdrawn at specific time intervals (2 min) and filter. An equal amount of fresh dissolution medium is replaced immediately following withdrawal of test sample. The percentage of drug released at various intervals is calculated using beer-lambert's law. The values are represented through the graph (Figs. 4-7).

\section{Stability studies [10]}

The selected formulation was packed in amber-colored bottles, which were tightly plugged with cotton and capped. They were then stored at $40^{\circ} \mathrm{C} / 75 \%$ RH for 3 months and evaluated for their physical appearance, 
drug content and in vitro dispersion time at specified intervals of time.

Statistical analysis of the formulations and selection of optimized formulation

Statistical analysis was performed by $2^{2}$ factorial design by employing design expert 10 software and the formulations were analyzed for various parameters such as ANOVA, half normal and normal plots, contour plot, and overlay plot. The significance values " $p$ " were noted for the formulations containing various diluents and superdisintegrants separately and the optimized formulation was selected based on those values. The values were represented in Table 3 and Fig. 8-10.

\section{RESULTS AND DISCUSSIONS}

The standard calibration curve was constructed for naratriptan pure drug in $\mathrm{pH} 6.8$ phosphate buffer by UV-spectrophotometer, and the maximum wavelength was found to be $221 \mathrm{~nm}$. The values were found to be linear, and linearity is expressed by the value of correlation coefficient $\mathrm{R}^{2}=0.993$.

Table 7: Post-compression parameters of formulations $F_{1}-F_{33}$

\begin{tabular}{|c|c|c|c|}
\hline $\begin{array}{l}\text { Tablet } \\
\text { formulation }\end{array}$ & $\begin{array}{l}\% \text { of drug } \\
\text { Content }\end{array}$ & $\begin{array}{l}\text { Wetting } \\
\text { time (s) }\end{array}$ & $\begin{array}{l}\text { Water } \\
\text { absorption ratio }\end{array}$ \\
\hline F1 & $95.23 \pm 0.25$ & 18 & 23 \\
\hline $\mathrm{F} 2$ & $94.16 \pm 0.47$ & 15 & 20 \\
\hline F3 & $96.65 \pm 0.58$ & 19 & 24 \\
\hline F4 & $97.45 \pm 0.96$ & 17 & 22 \\
\hline F5 & $96.57 \pm 0.64$ & 16 & 21 \\
\hline F6 & $95.52 \pm 0.16$ & 15 & 20 \\
\hline F7 & $94.56 \pm 0.32$ & 14 & 19 \\
\hline F8 & $96.31 \pm 0.02$ & 13 & 18 \\
\hline F9 & $97.20 \pm 0.48$ & 18 & 23 \\
\hline $\mathrm{F}_{10}$ & $96.66 \pm 0.53$ & 17 & 22 \\
\hline$F_{11}^{10}$ & $95.25 \pm 0.76$ & 15 & 20 \\
\hline $\mathrm{F}_{12}^{11}$ & $94.32 \pm 0.09$ & 13 & 18 \\
\hline $\mathrm{F}_{13}^{12}$ & $95.69 \pm 0.11$ & 14 & 19 \\
\hline $\mathrm{F}_{14}^{13}$ & $96.64 \pm 0.19$ & 15 & 20 \\
\hline $\mathrm{F}_{15}^{14}$ & $97.71 \pm 0.51$ & 16 & 21 \\
\hline $\mathrm{F}_{16}^{15}$ & $94.40 \pm 0.42$ & 13 & 18 \\
\hline $\mathrm{F}_{17}^{16}$ & $95.58 \pm 0.60$ & 17 & 22 \\
\hline $\mathrm{F}_{18}^{17}$ & $96.61 \pm 0.53$ & 18 & 23 \\
\hline $\mathrm{F}_{19}^{18}$ & $97.74 \pm 0.37$ & 16 & 21 \\
\hline $\mathrm{F}_{20}^{19}$ & $98.87 \pm 0.28$ & 20 & 25 \\
\hline $\mathrm{F}_{21}^{20}$ & $96.55 \pm 0.13$ & 17 & 22 \\
\hline $\mathrm{F}_{22}^{21}$ & $97.14 \pm 0.46$ & 16 & 21 \\
\hline $\mathrm{F}_{23}$ & $96.20 \pm 0.30$ & 18 & 23 \\
\hline $\mathrm{F}_{24}^{23}$ & $97.07 \pm 0.55$ & 15 & 20 \\
\hline $\mathrm{F}_{24}^{24}$ & $95.63 \pm 0.41$ & 19 & 24 \\
\hline $\mathrm{F}_{26}^{25}$ & $98.87 \pm 0.80$ & 13 & 18 \\
\hline $\mathrm{F}_{27}^{26}$ & $97.60 \pm 0.26$ & 17 & 22 \\
\hline $\mathrm{F}_{28}^{27}$ & $99.14 \pm 0.71$ & 14 & 19 \\
\hline $\mathrm{F}_{29}^{28}$ & $98.77 \pm 0.11$ & 12 & 17 \\
\hline $\mathrm{F}_{30}^{29}$ & $97.49 \pm 0.35$ & 15 & 20 \\
\hline $\mathrm{F}_{31}^{30}$ & $98.84 \pm 0.47$ & 16 & 21 \\
\hline $\mathrm{F}_{32}^{31}$ & $98.56 \pm 0.52$ & 16 & 21 \\
\hline $\mathrm{F}_{33}^{32}$ & $98.88 \pm 0.63$ & 17 & 22 \\
\hline
\end{tabular}

Table 8: comparison of best formulation with marketed product (Elipran $20 \mathrm{mg}$ tablet $\mathrm{mfg}$ : intas form: tablet)

\begin{tabular}{lll}
\hline Time (min) & $\mathbf{F}_{\mathbf{2 9}}$ & $\mathbf{m . p}$ \\
\hline 0 & $0 \pm 0.00$ & $0 \pm 0.00$ \\
5 & $40.14 \pm 0.021$ & $38.89 \pm 0.026$ \\
10 & $54.39 \pm 0.013$ & $53.12 \pm 0.038$ \\
15 & $68.84 \pm 0.042$ & $67.6 \pm 0.047$ \\
20 & $77.16 \pm 0.036$ & $75.48 \pm 0.065$ \\
25 & $86.59 \pm 0.038$ & $84.41 \pm 0.012$ \\
30 & $99.67 \pm 0.06$ & $97.74 \pm 0.023$ \\
\hline
\end{tabular}

The IR graphs of the pure drug and the best formulation $\mathrm{F}_{29}$ were found to have similar peaks of the functional groups, and this shows that there is no interaction between the drug and excipients that are used to formulate the orodispersible tablets. Hence, there will be no change in the maximum wavelength and drug release of the formulations.

The angle of repose of different formulations was $\leq 34.89$ which indicates that material had good flow property. Hence, it was confirmed that the flow property of blends was free-flowing. The bulk density of blend was found between $0.450 \mathrm{~g} / \mathrm{cm}^{3}$ and $0.496 \mathrm{~g} / \mathrm{cm}^{3}$. Tapped density was found between $0.509 \mathrm{~g} / \mathrm{cm}^{3}$ and $0.568 \mathrm{~g} / \mathrm{cm}^{3}$. These values indicate that the blends had good flow property. Carr's index for all the formulations was found to be between 8.28 and 18.62 and Hausner's ratio from 1.09 to 1.228 which reveals that the blends have good flow character.

Hardness of the tablet was acceptable and uniform from batch to batch variation, which was found to be $\leq 3.89 \mathrm{~kg} / \mathrm{cm}^{2}$. All the formulations passed the weight variation test as the $\%$ weight variation was within the pharmacopoeial limits of the tablet weight. Friability values were found to be $<1 \%$ in all the formulations F1-F33 and considered to be satisfactory ensuring that all the formulations are mechanically stable. Disintegration values were found to be within 27-39 s. Hardness should be less for rapid disintegration not much weight variation is to be shown by the tablets. Rapid disintegration within no time shows the faster activity of the drug.

The drug content uniformity was found between $96.11 \%$ and $99.85 \%$. The wetting time of the formulations was found to be between 12 and $20 \mathrm{~s}$. The water absorption ratio was found to be in the range of 17-25. The drug dose that has been incorporated to formulate tablets was present interact in them even after tablet formulation is done. Wetting time optimum gives us the rapid absorption of water or buffer by the tablets that result in rapid disintegration. Water absorption ratio if high it absorbs more water in less time disintegrates and solubilizes easily.

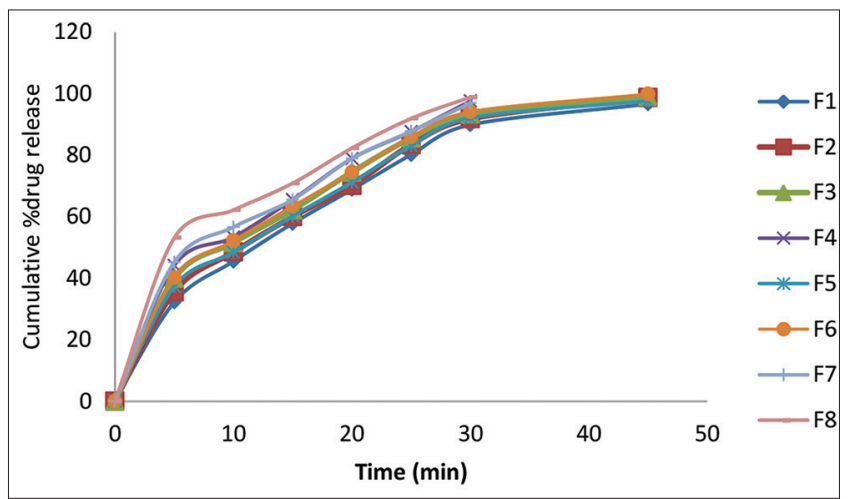

Fig. 4: Cumulative drug release graphs of Eletriptan formulations $\mathrm{F}_{1}-\mathrm{F}_{8}$

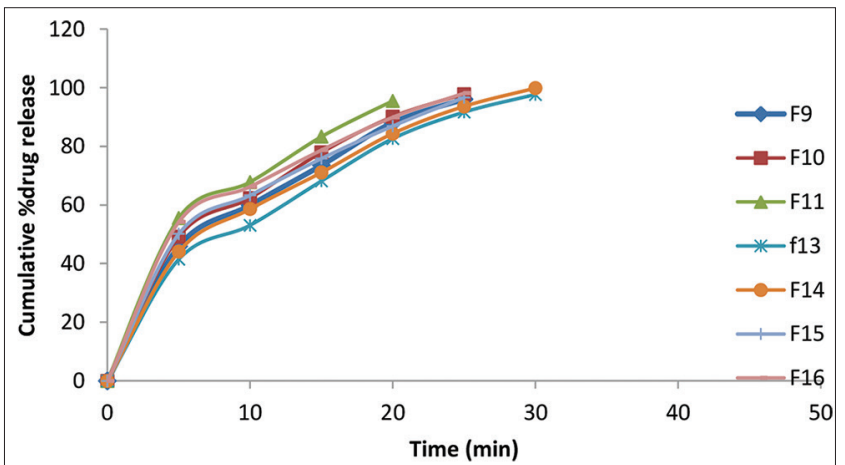

Fig. 5: Cumulative drug release graphs of Eletriptan formulations $F_{9}-F_{16}$ 


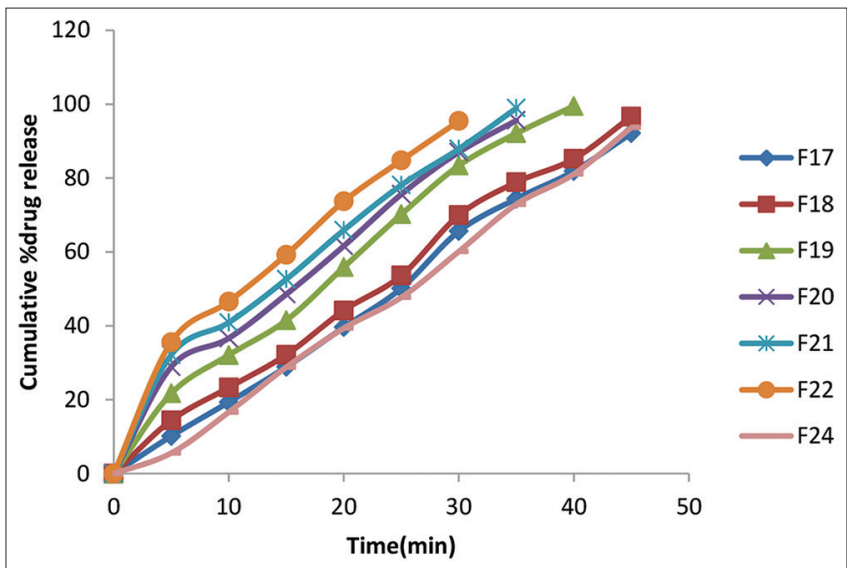

Fig. 6: Cumulative drug release graphs of Eletriptan formulations

$$
\mathrm{F}_{17}-\mathrm{F}_{24}
$$

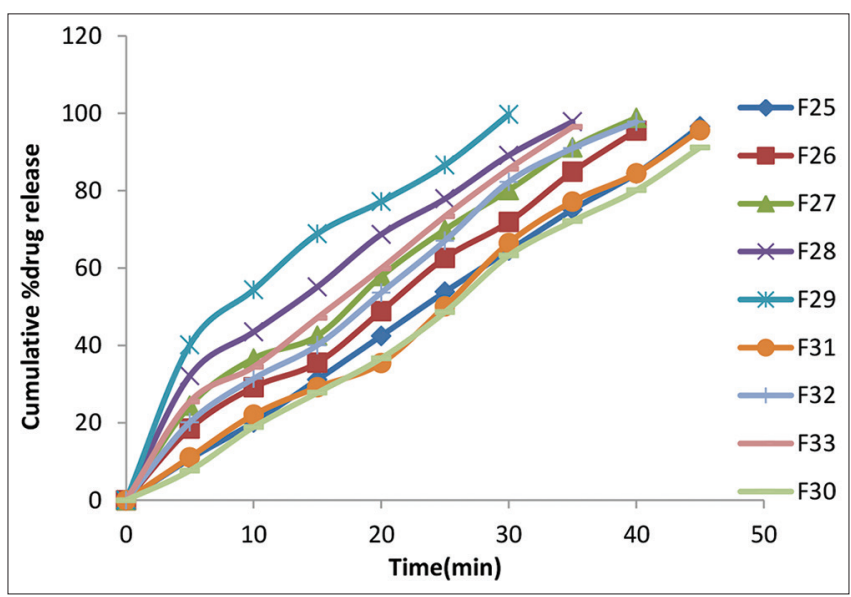

Fig. 7: Cumulative drug release graphs of Eletriptan formulations $\mathrm{F}_{25}-\mathrm{F}_{33}$

The cumulative drug release values were found for all the formulations, and the best formulation among first 16, i.e., formulation F12 containing mannitol shows $98.8 \%$ drug release in 25 min was taken for further study containing various superdisintegrants. Formulation F12 has been selected for further study depending on the drug release, and other 17 formulations were prepared using three different superdisintegrants in different concentrations. Among the above formulations F17 to F29, formulations F29 containing cross carmellose sodium as superdisintegrant and spraydried lactose as diluent has shown best drug release of $99.6 \%$ in 30 min. The best formulation F29 follows first-order kinetics and was subjected to accelerated stability studies for 3 months. The drug release studies were conducted on the formulation after 3 months, and there was no change which shows that the formulation is stable.

The best formulation or the optimized formulation that is obtained was compared with the marketed tablet Elipran $20 \mathrm{mg}$ to determine the rate of drug release. The optimized formulation has shown $99.67 \%$ drug release in 30 min whereas marketed formulation has shown $97.74 \%$ in $30 \mathrm{~min}$. The drug release of optimized formulation has been rapid compared to marketed one thus it shows faster relief in case of migraine. The data is shown in Table 8.

\section{CONCLUSION}

The orodispersible tablets of Eletriptan were formulated using various concentrations of diluents and various superdisintegrants in various concentrations. Thus, one best formulation from the diluents was selected, and that diluent concentration was taken as optimum concentration and using it various formulations containing

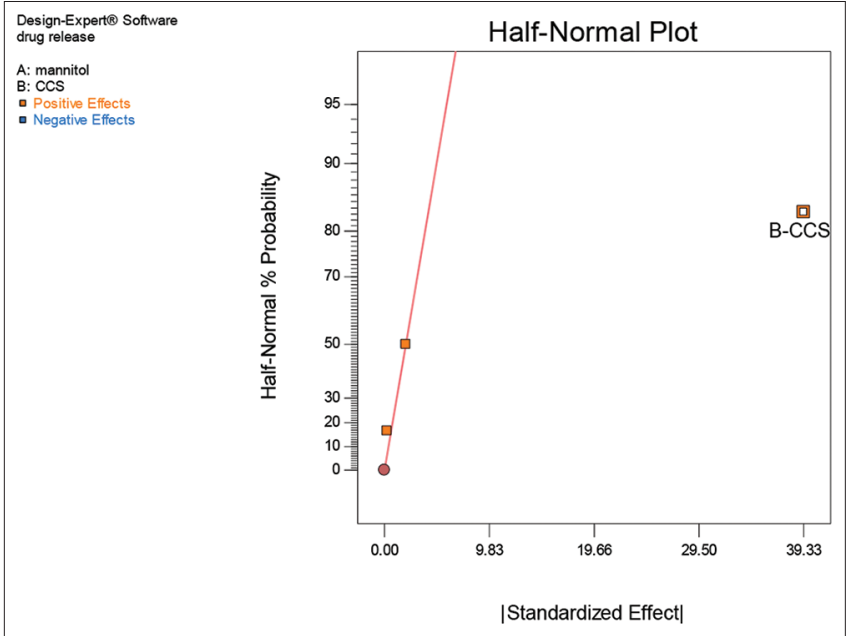

Fig. 8: Half-normal plot of eletriptan and cross carmellose sodium formulations by $2^{2}$ factorial designs

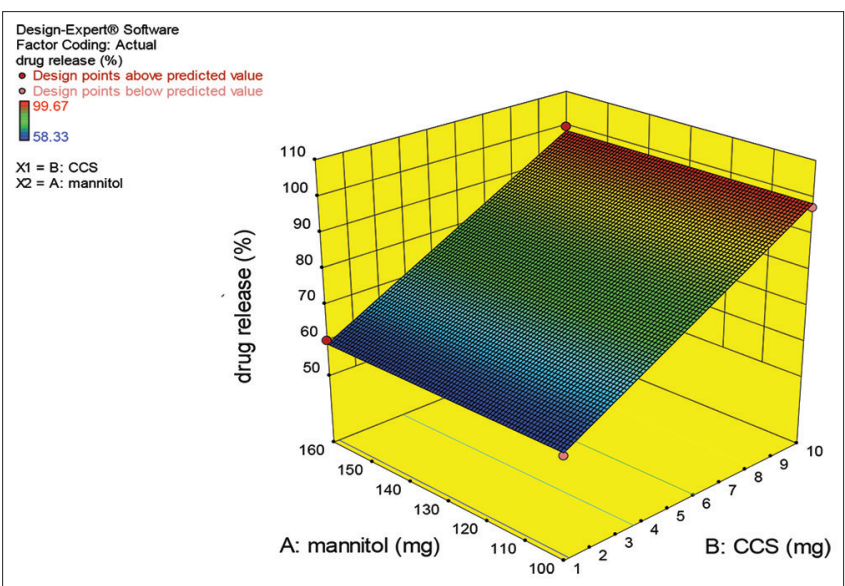

Fig. 9: Three-dimensional surface graph of Eletriptan mannitol and cross carmellose sodium by $2^{2}$ factorial design

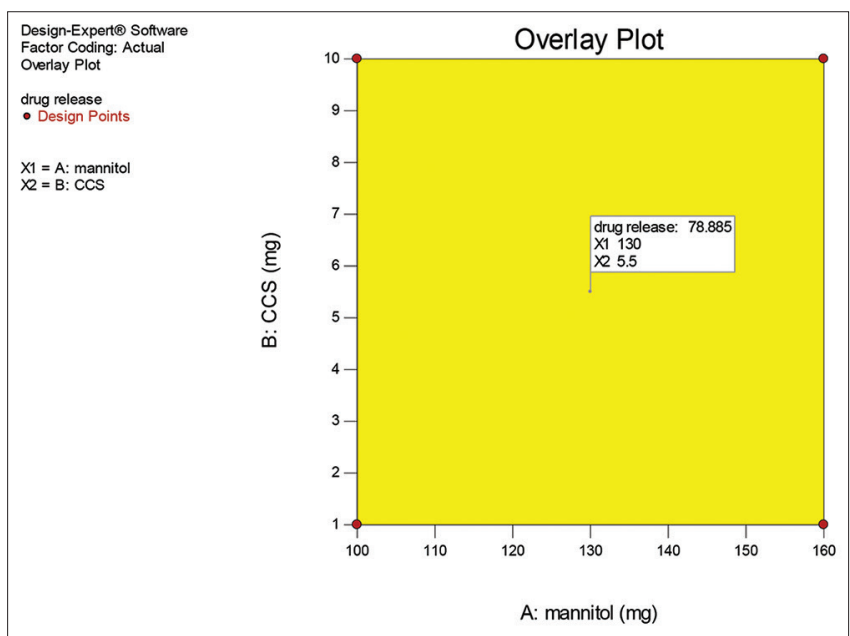

Fig. 10: Overlay plot of Eletriptan mannitol and cross carmellose sodium formulations by $2^{2}$ factorial design

superdisintegrants were prepared and based on the drug release the optimized and best formulation was selected. Thus, Eletriptan can be formulated as orodispersible tablets which give a rapid release and quick relief from the migraine headache. 


\section{AUTHORS CONTRIBUTION}

Y. Sirisha has carried out the research work successfully and obtained the results that were reported under the guidance of the two authors. Dr. T.E.G.K. Murthy has given the innovative idea of research that has not been explored and guided Y. Sirisha in every step of research Dr.A.Srinivasa Rao has provided the required resources for the research work and constantly supported the corresponding author to carryout the research work.

\section{CONFLICT OF INTEREST}

We here by declare that there are no conflicts of interest regarding the article and it is an original research work that has been carried out in the active guidance of the authors. We had not communicated or published this article in any other journal and we agrre for publication of this article in your journal.

\section{REFERENCES}

1. Kothapuvari PK, Rawat S, Bhikshapathi DV. Preparation, optimization and in vivo evaluation of eletriptan hbr fast dissolving oral films. Int J Drug Deliv 2015;7:141-54.

2. Damle C, Padalkar RR, Darandal SS, Mrinalini C. Formulation development and evaluation of novel mouth dissolving drug delivery system of Eletriptan hydrobromide. World J Pharm Pharm Sci 2016;5:1590-604.

3. Dey P, Maiti S. Orodispersible tablets: A new trend in drug delivery. J Nat Sci Biol Med 2010;1:2-5.

4. Sinko PJ. Martin's Physical Pharmacy and Pharmaceutical Sciences. $5^{\text {th }}$ ed. New York: Lippincott Williams and Wilkins; 2006. p. 557.

5. Government of India Ministry of Health \& Family Welfare. Indian Pharmacopoeia. Delhi: Controller of Publications; 2007. p. 1689-90.

6. Liberman H, Lachman L. The Theory and Practice of Industrial Pharmacy. $3^{\text {rd }}$ ed. Mumbai: Verghese Publication House; 1991. p. 171-93.

7. Jeevanandham S, Dhachinamoorthi D, Chandrasekhar KB, Muthukumaran M, Sriram N. Formulation and evaluation of naproxen sodium orodispersible tablets-A sublimation technique. Asian J Pharm 2010;4:48-51.

8. Ministry of Health and Family Welfare, Govt. of India Controller of Publications. Pharmacopoeia of India. New Delhi: Ministry of Health and Family Welfare, Govt. of India Controller of Publications; 1996. p. 735.

9. Lachman L, Lieberman HA, Kinig JL. The Theory and Practice of Industrial Pharmacy. 4th ed. Bombay: Varghese Publishing House; 1991. p. 67-8].

10. Siji RR, Shanmuganathan S, Sekharan TR, Senthil Kumar SR, Thang AT. Formulation and evaluation of mouth dissolving Famotidine tablet. Int J Chem Technol Res 2009;1:1251-6. 